\title{
Estimation of Passenger Car Equivalents for Basic Freeway Sections at Different Traffic Conditions
}

\author{
Jalal Taqi Shaker Al-Obaedi \\ College of Engineering, University of Al-Qadisiya, Al-Qadisiya, Iraq \\ Email: Jalal.alobaedi@qu.edu.iq
}

Received 21 March 2016; accepted 26 April 2016; published 29 April 2016

Copyright (C) 2016 by authors and Scientific Research Publishing Inc.

This work is licensed under the Creative Commons Attribution International License (CC BY). http://creativecommons.org/licenses/by/4.0/

(c) (i) Open Access

\begin{abstract}
Passenger car equivalent (PCE) is an important factor which is used to convert traffic volumes containing proportions of heavy good vehicles (HGVs) to a unify measure containing only passenger cars units (PCU). This paper uses large data base of real traffic raw data extracted from loop detector before being aggregated to estimate PCEs. These detectors are located on the M25 and the M42 motorway sites in the United Kingdom. The selected sites represent basic freeway segments as they are far away from the influence of entrance (on ramp) and exit (off ramp) sections. The data are filtered properly so as to estimate passenger car equivalents (PCEs) using lagging headway method for close following situations at different speed ranges. The results suggest that for the same location, the equivalency factors are varies significantly based traffic speed. However, it is proved that such variation with traffic speed is influenced by the differences in lengths between HGVs and cars. Regression models have also been developed linking the PCEs with traffic speed.
\end{abstract}

\section{Keywords}

Passenger Car Unit, Passenger Car Equivalent, Trucks Equivalency Factor, Lagging Headway, Close Following

\section{Introduction}

Passenger car equivalent (PCE) is an important factor which is used to convert traffic volumes containing proportions of heavy good vehicles (HGVs) to a unify measure containing only passenger cars units (PCUs). Such conversion is important for traffic studies since the description of traffic parameters such as capacity and speed 
is greatly influenced by the traffic mix proportions. For example, the capacity of a given section in units of $\mathrm{veh} / \mathrm{hr}$ is significantly vary with different proportion of HGVs while the use of capacity in units of pcu/hr provides clear idea about the actual capacity regardless the HGVs proportion [1].

In general, the presence of HGVs in traffic stream has a negative impact on a highway capacity for many reasons associated with HGVs length and HGVs acceleration/deceleration and maneuvering abilities [2]. The effect of HGVs length is represented by increasing headways and hence reduces capacity. In addition, HGVs have lower acceleration/deceleration abilities and increase HGVs negative impact at lower speeds and at upgrade sections. Therefore, the typical PCE values should be higher than a single passenger car.

Many methods are described in previous literature to estimate PCE [3]. The main of these methods includes the constant capacity ratio method [4], the equal-density method [5] and [6], queue discharge method [7], and the lagging headway method [8].

According to [9], the constant capacity method is relevant to traffic simulation models. The PCE is estimated based on some trials and the selected value should provide constant capacity in (pcu/hr) for different HGVs percentages. Equal density method estimates PCE based on speed difference between flow rates containing only passenger cars and flow rates containing HGVs [10]. Similarly, queue discharge method compares the discharge flow rates at congested situations in the case of mixed traffic with the case of traffic containing only passenger cars [7].

Lagging headway method [3] estimates the PCE as the ratio between lagging headway when the following vehicle is HGV to the lagging headway when the following vehicle is a small car based on Equation (1). The illustration of these two lagging headways is presented in Figure 1 which also shows other parameters used in the paper including the following headway and the following distance. The following headway represents the time, in seconds, from the rear of the leading vehicle to the front of the following vehicle whereas the following distance measures the clear spacing, in meters, between any two successive vehicles. It should be noted here that the lagging headway differs from the well-known time headway as the latter represents the time, in seconds, from the front of the leading vehicle to the front of the following one.

$$
P C E=\frac{h_{t}}{h_{c}}
$$

where:

$h_{t}$ is the average lagging time headway maintained by HGV.

$h_{c}$ is the average lagging time headway maintained by small car.

Al-Kaisy et al. [7] applied the queue discharge method and found that the PCE was about 2.36 at basic freeway segment with no longitudinal grade. Sarraj [11] estimated PCE at signalized intersection in Gaza using video recordings data and found that PCE was about 2.3 for heavy trucks. The highway capacity manual [1] suggested that PCEs varied based on type of terrains and length of the grads. The recommended PCE value was 1.5 for level terrain segments. Subhi [12] estimated PCE at signalized intersection in Iraq and found a value of about 2.0. Giuffrè, et al. [13] applied Aimsum micro-simulation model and stated that PCEs were increasing with increasing of traffic flow rates. Yeung, et al. [14] applied the headway method in situations where HGVs were imposed by speed limits of about $60-70 \mathrm{~km} / \mathrm{hr}$. There finding is that the PCE was about 1.53 and 2.75 for light goods and heavy goods vehicles, respectively.

So far, some studies focus only on discharge flow conditions while others focus on moderate traffic. The effect of traffic speed on PCEs has got little attention. In addition, the effect of selected lane on PCEs was not examined. This paper uses large data base of real traffic data taken from loop detector on the M42 and the M25 motorway sites in the United Kingdom to estimate PCEs at different traffic conditions. The effect of driving lane is also considered. The source of the electronic data used and its size (more than 4 million cases of successive vehicles) make it more reliable than other sources of data used in previous literature.

\section{Methodology}

As described above, this paper uses real raw traffic data taken from loop detector on the M42 and the M25 motorway sites in the United Kingdom to estimate PCEs. This section describes the data and method used to filter and analyze the available data. 

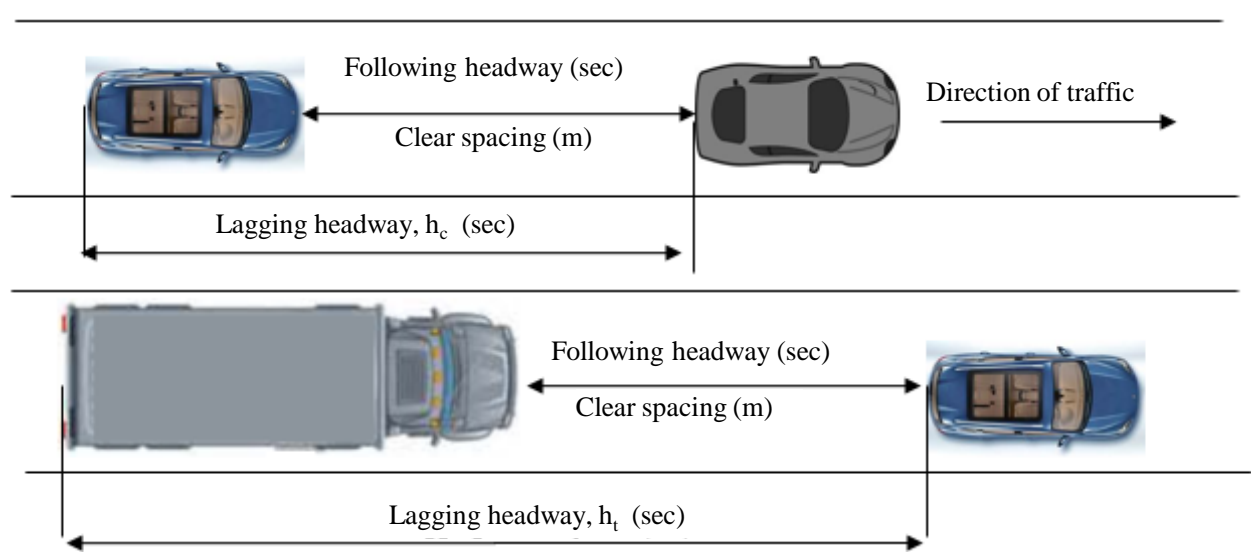

Figure 1. Illustration of lagging headway, clear spacing, and following headway.

\subsection{Description of the Data}

The data represents a full 14 days of individual vehicles raw data, extracted from inductance loop detectors on sections from the M42 between Junctions 5 - 6 and the M25 between Junctions 15 - 16. The M25 and the M42 have four lanes and three lanes per direction, respectively. According to the UK regulations, HGVs are banned from using the offside lane for motorways with 3 or more lanes. Speed, headway and length for each vehicle reaching the detector for each specific lane, were presented in the data. In total, the data represents more than 4 million leader/follower cases. This source of data, with such size, may be regarded to be more reliable than the data used in other literatures.

\subsection{Method of Estimating PCE}

As described above, there are many methods to estimate PCE. Among these methods, lagging headway method is selected in this research because it is believed that the time headway (as previously explained in Figure 1 above) is the most critical microscopic term related to the flow rate as well as the capacity of a section. In addition, the lagging headway parameter is the only one that could directly represents the effect of the vehicle types through including its length. The PCE is estimated using Equation (1) above after estimating the lagging headway according to the following vehicles' types. The lagging headway is estimated by converting the available time headway ( $h$, front to front) to the following headway based on speed of the following vehicle $\left(S_{F}\right)$ and length of the leading vehicle $\left(L_{L}\right)$ using Equation (2). The following headway is then used in estimation the lagging headway based on Equation (3) using speed $\left(S_{F}\right)$ and length of the following vehicle $\left(L_{F}\right)$.

$$
\begin{gathered}
\text { Following headway }=h-\frac{L_{L}}{S_{F}} \\
\text { Lagging headway = Following headway }+\frac{L_{F}}{S_{F}}
\end{gathered}
$$

\subsection{Defining the Types of Vehicles}

The types of vehicles are not readily obtained from the data provided (i.e. Cars or HGVs). Therefore, and for the purpose of this study, it is important to define the type of each vehicle based on its length. Similar procedure to that adopted by [15] when they used a $6.6 \mathrm{~m}$ vehicle length to distinguish between cars and HGVs. Any vehicle has a length less than $6.6 \mathrm{~m}$ is regards as a small car (i.e. pcu) while any longer vehicle is regarded as HGV.

\subsection{Procedure of Filtering the Data}

In order to estimate the PCE, it is required to focus only on close following situations [16]. Previous research works stated that close following situations could be identified by selecting suitable following headway (from rear of the leading vehicle to the front of the leading vehicle, see Figure 1). A value of 2 seconds is used which 
is similar to that suggested by [2] and [17]. In addition a value of $1.5 \mathrm{~m} / \mathrm{s}(5.4 \mathrm{~km} / \mathrm{hr})$ was selected as the maximum relative speed difference between the leading and the following vehicles. This value was suggested by [18] and [19] to represent the maximum speed difference at steady state conditions (car following regime).

In order to analyze such large sample of data which represents more than 4 million pairs of leader/follower, a computer program using FORTRAN was written for this purpose. At first, the data were filtered to be separated on lane bases. The separated data have then been analyzed further to filter the data using the above described methodology. The speeds were grouped for every $10 \mathrm{~km} / \mathrm{hr}$ in order to show the effect of traffic condition on PCEs.

\subsection{Size of the Analyzed Sample}

While the initial data represents over 4 million cases, Table 1 represents the size of the remaining sample after filtering the raw data based on the methodology described above. In total, the remaining sample after the filtering process was 679,574 close following cases.

\section{Results and Discussion}

As discussed above, the UK regulations do not allow for HGVs to use the offside lane for motorways with 3 or more lanes. Therefore, in all most, no HGVs data were available for the fourth lane of the M25 (4-lane motorway) and the third lane of the M42 (3-lane motorway).

For the M25 where the HGVs are more concentrated in lane 1 and 2 and banned from use of lane 4, the results of the data analysis are shown in Figure 2. The figure shows the PCEs for lanes 1, 2 and 3 and for speed range from 15 to $100 \mathrm{~km} / \mathrm{hr}$. In general, the figure shows that the PCEs for HGVs in lane 1 and lane 2 are identical which are significantly higher than PCEs for HGVs in lane 3. The figure suggests that the PCEs are decreasing with increasing of traffic speed. This is due to a fact that the PCEs are influenced by length of HGVs and therefore the effect of this length is decreasing with increasing of speed.

The results in Figure 2 for lanes 1 and 2 suggest that the PCE is about 1.8 at queue discharge conditions (when average speed is about $20 \mathrm{~km} / \mathrm{hr}$ or less). For congested speed of less than $50 \mathrm{~km} / \mathrm{hr}$, the PCE is about 1.5. For higher speeds the PCEs were between 1.3 and 1.4. The latter values are lower than PCE of 1.5 which is recommended by the Highway Capacity Manual [1].

To represent the effect of HGVs length of PCEs, Figure 3 shows imaginary case when the lengths of HGVs and cars are assumed to be similar while the other parts in the data are still real. The Figure suggests that the PCEs are more or less equal to 1 regardless the average speed value. This provides the evidence that the variation in PCEs with traffic speed is only related to the differences in lengths between HGVs and cars.

Further investigation to explain why the PCEs for HGVs in lane 3 were lower than HGVs values in lanes 1 and 2 suggested that the reason is related to the differences of HGVs lengths used these lanes. It is found that the average length of HGVs length in lane 3 is about two meters less than average HGVs lengths in lanes 1 and 2 for the same motorway (M25). The HGVs lengths were $13.1 \mathrm{~m}$ in lane 1, $12.8 \mathrm{~m}$ for HGVs in lane 2, and 11.0 in lane 3. It seems that HGVs with high length did not use the third lane of the M25 less frequently since such lane might regard as one of the fast lanes.

For the M42, where HGVs were more concentrated in lane 1 and banned from use of lane 3, the results of the data analysis are shown in Figure 4. The figure shows the PCEs for lanes 1 and 2 for speed range from 15 to $100 \mathrm{~km} / \mathrm{hr}$. The results in Figure 4 have similar trends to those results presented in Figure 2 for the M25. The PCEs for HGVs in lane 1 are significantly higher than PCEs for HGVs in lane 2 for reasons related to the differences in the lengths of HGVs use lanes 1 and 2. The average lengths of HGVs used lane 2 was about $1 \mathrm{~m}$ less than HGVs lengths used lane 1.

The results for lane 1 of the M42 were similar to those for lanes 1 and 2 for the M25 since HGVs lengths were approximately similar. This is could be explained through presenting in Figure 5 which shows PCEs for these lanes.

The results presented from the M25 and the M42 could be transferred to more useful regression models linking the PCEs with traffic speeds $(\mathrm{km} / \mathrm{hr})$. These models with their coefficients of determinations $\left(\mathrm{r}^{2}\right)$ are shown in Table 2. The $r^{2}$ coefficients suggest strong relationship between traffic speed and PCEs. It should be noted here that these suggested models for these motorways are applicable for speed ranges up to $100 \mathrm{~km} / \mathrm{hr}$. The model developed for lanes $1 \& 2$ on the M25 is suggested to be similar to that for lane 1 on the M42. 
Table 1. Analyzed sample size (veh) after data filtering process.

\begin{tabular}{cccccc}
\hline Motorway & \multicolumn{3}{c}{ M42 } & \multicolumn{2}{c}{ M25 } \\
\hline Headway Type & $h_{c}$ & & $h_{t}$ & $h_{c}$ & $h_{t}$ \\
No. of Headways & 161,593 & & 63,749 & 367,954 & 86,278 \\
Sub Total & & 225,342 & & & 454,232 \\
Total & & & 679,574 & \\
\hline
\end{tabular}

Table 2. The developed regression model for PCEs.

\begin{tabular}{ccccc}
\hline Lane & \multicolumn{1}{c}{ Model $^{2}$} & \\
\hline Motorway & $1 \& 2$ & PCE $=0.00009$ Speed $^{2}-0.0162$ Speed +2.0 & 0.97 \\
& 3 & PCE $=0.0001$ Speed $^{2}-0.016$ Speed +1.835 & 0.96 \\
M42 & 1 & PCE $=0.00009$ Speed $^{2}-0.0162$ Speed +1.992 & 0.96 \\
\hline
\end{tabular}
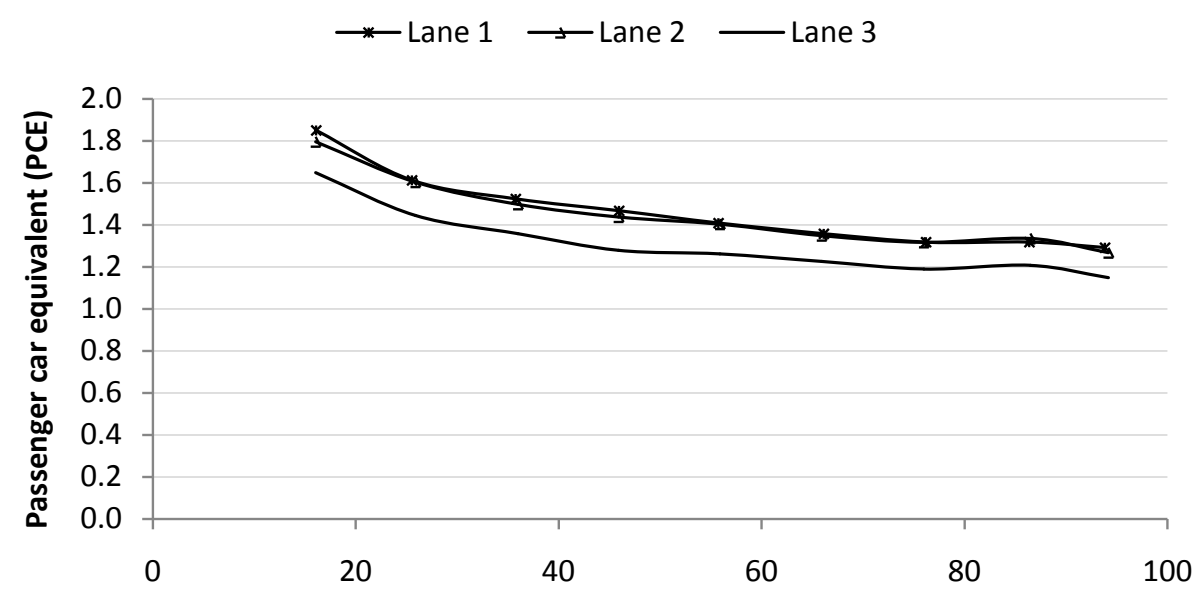

Average speed (km/hr)

Figure 2. PCEs based on the M25 data.

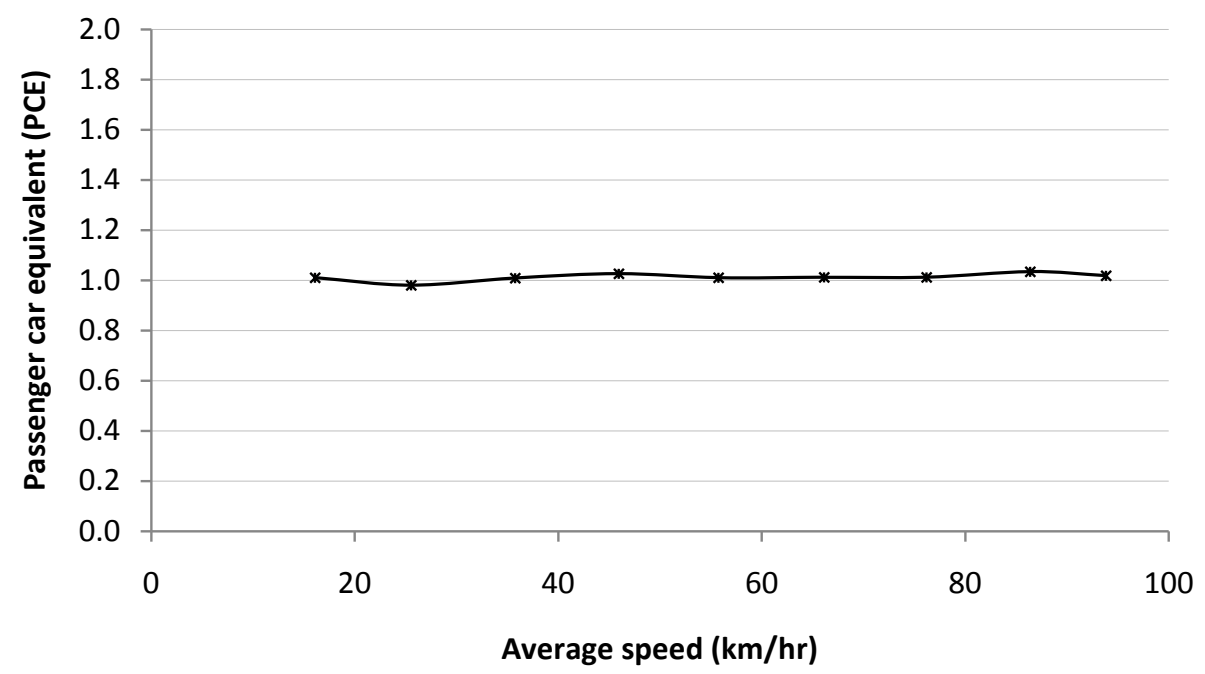

Figure 3. Imaginary case for PCEs when lengths of HGVs are equal to length of cars. 


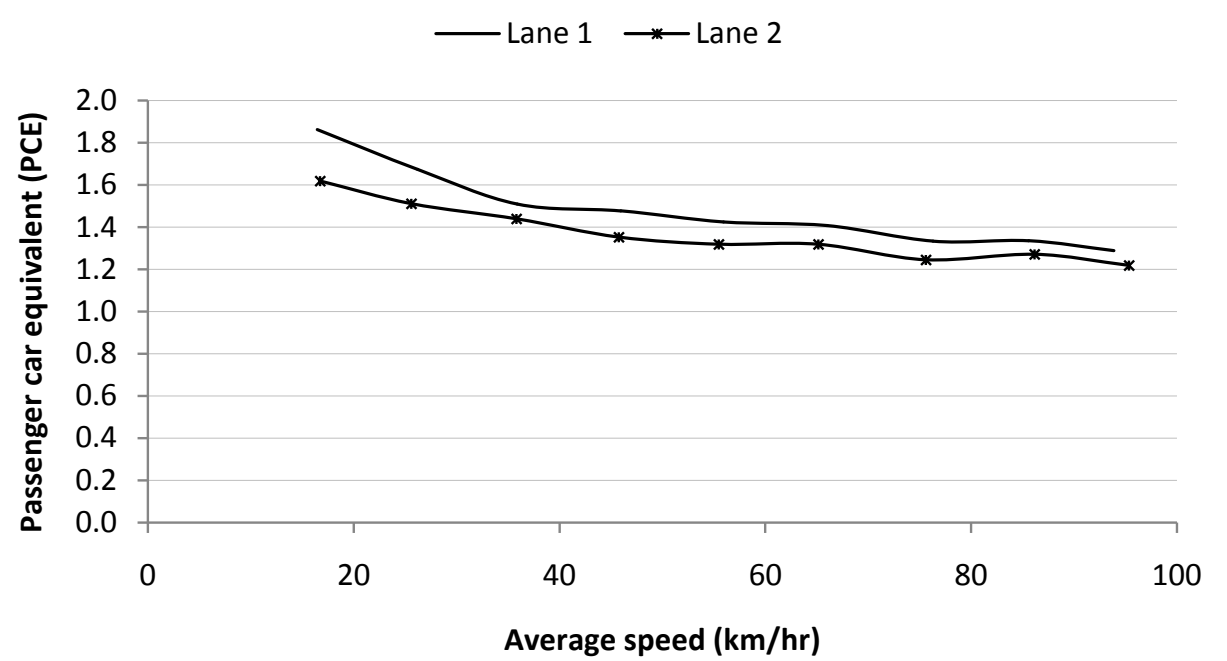

Figure 4. PCEs based on the M42 data.

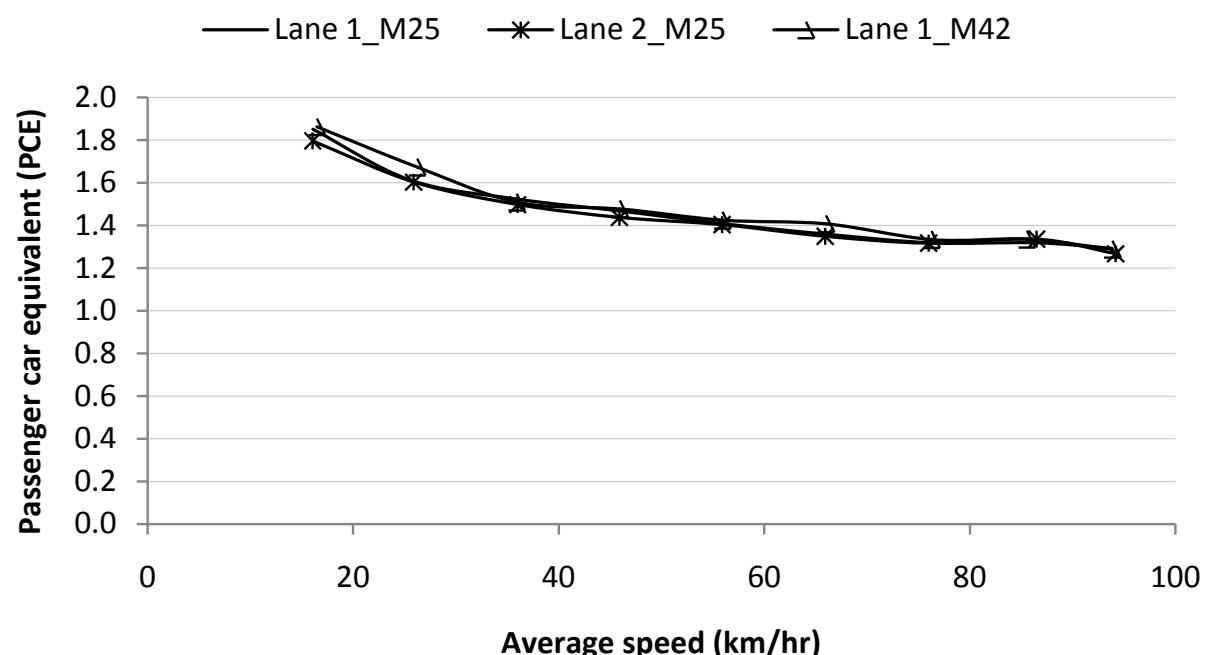

Figure 5. PCEs for lanes 1 and 2 of the M25 and for lane 1 of the M42.

\section{Conclusions}

This paper used large data base of real traffic raw data extracted from loop detector before being aggregated to estimate PCEs. These detectors were located on the M25 and the M42 motorway sites in the United Kingdom. The selected sites represented basic freeway segments as they were far away from the influence of merge and diverged section. The data provided the microscopic information for millions of cases of individual vehicles. The data were filtered properly so as to estimate PCEs, using lagging headway method, for close following situations at different speed ranges.

The results suggested that for the same location, the equivalency factors were varies significantly based traffic speed. However, it was proved that such variation with traffic speed was influenced by the differences in lengths between HGVs and cars. In addition, the obtained PCEs values, at congested situations, were higher than that recommended by the highway capacity manual and slightly lowered values at normal traffic conditions. Some variations in PCEs values were found on lane bases, however, further investigations suggested that such variation was only related to the differences in HGVs lengths used the available lanes. Regression models had also been developed linking the PCEs with traffic speed for speeds up to $100 \mathrm{~km} / \mathrm{hr}$.

The ongoing research work will try to model PCEs values through considering only the effective parameters based on the findings of the current work. 


\section{Acknowledgements}

The author wishes to thank Dr. Eddie Wilson (University of Bristol, UK) and Dr. Saad Yousif (University of Salford, UK) for providing the individual vehicles raw data from the M25 and the M42 motorway sites.

\section{References}

[1] Transportation Research Board (2010) Highway Capacity Manual (HCM). National Research Council, Washington DC.

[2] Yousif, S. and Al-Obaedi, J. (2011) Close Following Behavior: Testing Visual Angle Car Following Models Using Various Sets of Data. Transportation Research: F, 14, 96-110. http://dx.doi.org/10.1016/j.trf.2010.11.001

[3] Shalini, K. and Kumar, B. (2014) Estimation of the Passenger Car Equivalent: A Review. International Journal of Emerging Technology and Advanced Engineering, 4, 97-102.

[4] Alecsandru, C., Ishak, S. and Yan, Q. (2012) Passenger Car Equivalents of Trucks on Four-Lane Rural Freeways under Lane Restriction and Different Traffic Conditions. Canadian Journal of Civil Engineering, 39, 1145-1155.

[5] Webster, N. and Elefteriadou, L. (1999) A Simulation Study of Truck Passenger Car Equivalents (PCE) on Basic Freeway Sections. Transportation Research: B, 33, 323-336. http://dx.doi.org/10.1016/S0965-8564(98)00036-6

[6] Demarchi, S.H. and Setti, J.R. (2003) Limitations of Passenger-Car Equivalent Derivation for Traffic Streams with More than One Truck Type. Transportation Research Record: Journal of the Transportation Research Board, 1852, 96-104. http://dx.doi.org/10.3141/1852-13

[7] Al-Kaisy, A.F., Hall, F.L. and Reisman, E.S. (2002) Developing Passenger Car Equivalents for Heavy Vehicles on Freeways during Queue Discharge Flow. Transportation Research: A, 36, 725-742.

[8] Ahmed, A., Van Boxel, D., Volovski, M., Anastasopoulos, P.C., Labi, S. and Sinha, K.C. (2011) Passenger Car Equivalents Based on Lagging Headways for Basic Freeway Segments. Journal of Transportation of the Institute of Transportation Engineers, 2, 5-17.

[9] Ahmed, U. (2010) Passenger Car Equivalent Factors for Level Freeway Segments Operating under Moderate and Congested Conditions. Master Theses, Marquette University, Milwaukee.

[10] Rahman, M. and Nakamura, F. (2005) Measuring Passenger Car Equivalents for Non-Motorized Vehicle (Rickshaws) at Mid-Block Sections. Journal of the Eastern Asia Society for Transportation Studies, 6, 119-126.

[11] Sarraj, Y.R. (2008) Passenger Car Equivalents at Signalized Intersections for Heavy and Medium Trucks and Animal Driven Carts in Gaza, Palestine. International Journal of Emerging Technology and Advanced Engineering, 4, 80-88.

[12] Subhi, A. (2013) Estimating the Passenger Car Equivalent (PCE) for Different Type of Vehicles on the Signalized Intersections. Engineering \& Technology Journal, 31, 38-49.

[13] Giuffrè, G., Granà, A., Mauro, R., Silva, A.B. and Chiappone, S. (2015) Developing Passenger Car Equivalents for Freeways by Microsimulation. Transportation Research Procedia, 10, 93-102. http://dx.doi.org/10.1016/j.trpro.2015.09.059

[14] Yeung, J.S., Wong, Y.D. and Secadiningrat, J.R. (2015) Lane-Harmonized Passenger Car Equivalents for Heterogeneous Expressway Traffic. Transportation Research: A, 78, 361-370.

[15] Yousif, S., Al-Obaedi, J. and Henson, R. (2013) Drivers’ Lane Utilization for United Kingdom Motorways. Journal of Transportation Engineering, 139, 441-447.

[16] Al-Kaisy, A., Jung, Y. and Rakha, H. (2005) Developing Passenger Car Equivalency Factors for Heavy Vehicles during Congestion. Journal of Transportation Engineering, 131, 514-523.

[17] Brackstone, M., Waterson, B. and McDonald, M. (2009) Determinants of Following Distance in Congested Traffic. Transportation Research: F, 12, 131-142.

[18] Sayer, J.R., Mefford, M.L. and Huang, R. (2003) The Effect of Lead Vehicle Size on Driver Following Behavior: Is Ignorance Truly Bliss? Proceedings of the 2nd International Driving Symposium on Human Factors in Driver Assessment, Training and Vehicle Design, University of Iowa, Park City, 21-24 July 2003, 221-225.

[19] Zhang, X. and Bham, G.H. (2007) Estimation of Driver Reaction Time from Detailed Vehicle Trajectory Data. Proceeding of the 18th IASTED International Conference, ACTA Press Anaheim, 574-579. 